\title{
An Empirical Analysis of Performance Evaluation of University Teachers Based on KPI
}

\author{
Chuanshu Zhu \\ Chongqing College of Finance and Economics, 402160 Chongqing, China
}

\begin{abstract}
Except for the influential graduates, the content of the development core of universities needs to improve the scientific allocation of teacher resources, and the most relevant content to human resource of teacher is the salary incentive system. While the system related to performance appraisal system is the performance assessment system, so the sound and perfect performance appraisal system of teachers in Colleges and universities is conducive to the strategic development of university. This article uses KPI theory in index design for quality content of university teachers, aiming at abstracting the key quality therefrom, constructing KPI performance appraisal system complying to $80 / 20$ and provide theoretical basis for improvement of human resources system in Colleges and promotion of the development of universities . This article provides five key types of quality of college teachers and refinable, quantifiable and behavioral key qualities, and conducts an empirical demonstration of weight of the corresponding index by the questionnaire survey, expert interview and AHP analysis method.
\end{abstract}

Keywords. performance appraisal; KPI theory; quality; weight; difference analysis

\section{Introduction}

KPI theory has made great achievements in the enterprise human resources management, and been for exploratory application in some colleges and universities, but is not that mature compared to application in enterprises. For application of KPI theory in performance appraisal of university teachers, this article conducts an analysis on various qualities for university teachers, expecting to provide the basis for abstraction of key qualities and quantifiable and behavioral quality factor designs.

Many scholars successively conducted researches on application of KPI theory in performance appraisal. They proposed some views and research methods that have certain inspiration effect on optimal allocation of resources of university teachers, among which: Lidong $\mathrm{Lu}(2008)$ conducted analysis and abstraction on performance drive factors in three levels of enterprise, department and staff, designed performance scorecards in three levels of performance management for Zhejiang Construction Group Construction Enterprise, as well as designed complete performance management procedure ${ }^{[1]}$; Qian Lu(2011) pointed out that we shall prepare good performance management system, including many indexes to form our own index base, and take into account the index base, as well as conduct timely modification, if necessary, to achieve merging of theory and practicality and design the $\mathrm{KPI}^{[2]}$ for performance management sys- tem of small and medium sized enterprises; Jingang Shao (2013) took J Company as the case to analyze the overall procedure of design, implementation and trial operation and evaluation of performance appraisal system based on KPI. Besides, based on the description of establishment procedure of KPI performance evaluation system, he proposed the insufficiency and improvement orientation ${ }^{[3]}$.

This article conducts analysis on factors related to performance appraisal of university teacher based the previous researches, discusses the key qualities of university teachers affecting the performance appraisal, gets the evaluation system of KPI performance appraisal index and proves the weight of each index, which provides the theoretical reference for development of university and management of human resources.

\section{The importance and affecting factors of performance appraisal of university teachers}

Performance refers to the result presented after an organization completes a job or task, and also the contribution made to that organization by staff, which is a kind of objective phenomenon and can be comprehensively predicted and evaluated in aspects of skill, opportunity, motivation, environment, etc.. Therefore, there is a performance formula as shown in Formula (1), where P refers 
to performance, $\mathrm{S}$ to skill, $\mathrm{O}$ to opportunity, $\mathrm{M}$ to Motivation and $\mathrm{E}$ to Environment.

$$
\mathrm{P}=\mathrm{F}(\mathrm{S}, \mathrm{O}, \mathrm{M}, \mathrm{E})
$$

Performance appraisal refers to the procedure and method $^{[4]}$ for an enterprise to, based on strategic objective line and by application of specific standard and index, evaluate the working behavior and performance obtained of staff and apply the evaluated result to provide positive guidance of future working behavior and performance for staff.

For university teachers, the scientific and reasonable performance appraisal is conducive to improvement of competitiveness, human resources management and self- management of teachers in university, among which, the importance of self-management of teachers can be improved by discovering the teacher's potential, promoting the teacher's self-motivation and the training. The Formula (2) can be used to represent the performance expression of performance of university teachers. In this formula, $\mathrm{P}$ refers to performance, I to individual factor, $\mathrm{O}$ to organizational factor and $\mathrm{T}$ to working factor.

$$
\mathrm{P}=\mathrm{f}(\mathrm{I}, \mathrm{O}, \mathrm{P})
$$

There are other factors related to performance of university teachers apart from the above three rule layers. To clarify the relevant factors of performance, this article provides the diagram as shown in Figure 1.

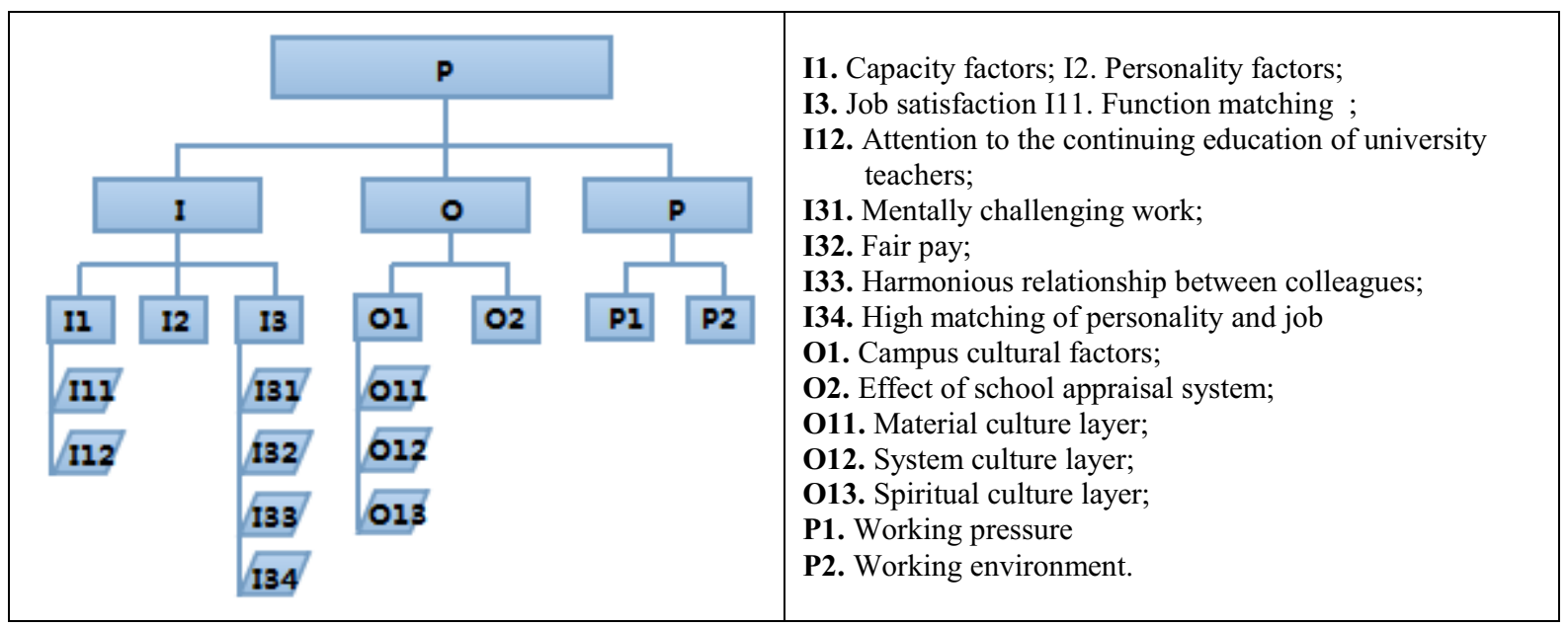

Figure 1. Diagram of factor structure related to performance of university teachers.

\section{Theoretical basis and design method of KPI performance appraisal}

\subsection{KPI Theoretical basis}

The Reference ${ }^{[5]}$ points out that KPI is the key performance index method, and a kind of strategic decomposition and control method designed for McKinsey Corporation to solve the strategic implementation issue. Its core idea is to find the key factor of success for successful implementation of corporation strategy based on $80 / 20$ rule, and determine the key performance index required for appraisal of strategic implementation procedure according to key factor of success ${ }^{[5]}$.

Among which, the $80 / 20$ theory represents that in the value creation procedure of an enterprise, $20 \%$ of key personnel creates $80 \%$ of enterprise value, and $80 \%$ of the tasks are completed by $20 \%$ of the key behaviors. The research content of KPI theory is the analysis and measurement of it, which is helpful for an enterprise to seize the key point of performance evaluation.
KPI is a kind of system appraisal evaluation system based on enterprise operation and management performance, used for appraisal and management of performance of evaluated persons. The index content of KPI must be quantified and behavioral and, if not, will be considered as incompliant to KPI requirement, which mainly shows the performance index having gain effect on organizational strategy. By commitment on KPI, the staff and management can therefore communicate with each other in aspects of working expectation, performance, future development, etc..

The difference of KPI index system and regular performance appraisal index system can be analyzed in aspects of A. assumption and premise, B. appraisal object, C. index generation, D.index source, E. Index construction and F. index application, as shown in Table 1, for the purpose of displaying the superiority of performance appraisal index system based on KPI as well as the simple classification of its applicability, leading it to provide better service for enterprise human resource management.

Table 1. List of difference between index system and regular performance appraisal index system based on KPI ${ }^{[6]}$.

\begin{tabular}{|l|l|l|}
\hline Type & KPI & Regular \\
\hline A & $\begin{array}{l}\text { Assume that people will take any necessary } \\
\text { actions to strive to achieve the established } \\
\text { objective. }\end{array}$ & $\begin{array}{l}\text { Assume that people will not take the initiative to achieve the } \\
\text { expected objective, or they are not clear about what shall be done } \\
\text { to achieve the objective, or the establishment and implementation } \\
\text { of enterprise strategy is non-relevant to regular staff. }\end{array}$ \\
\hline
\end{tabular}




\begin{tabular}{|c|c|c|}
\hline B & $\begin{array}{l}\text { Taking the strategy as the core, both the design } \\
\text { and implementation of performance appraisal } \\
\text { index system will serve the strategic objective. }\end{array}$ & $\begin{array}{l}\text { Taking the supervision and control as the core, both the } \\
\text { practicality and implementation of performance appraisal index } \\
\text { system serves the control objective, aiming at more efficient } \\
\text { control of individual behavior. }\end{array}$ \\
\hline $\mathrm{C}$ & $\begin{array}{l}\text { Performance appraisal index is generated by } \\
\text { decomposition level-by-level from top to } \\
\text { bottom of organizational strategic objective in } \\
\text { the enterprise. }\end{array}$ & $\begin{array}{l}\text { The performance appraisal index is generated by past performance } \\
\text { and objective of staff from top to bottom. }\end{array}$ \\
\hline $\mathrm{D}$ & $\begin{array}{l}\text { Performance appraisal index is originated from } \\
\text { requirements of organizational strategic } \\
\text { objective and competition. }\end{array}$ & $\begin{array}{l}\text { Performance appraisal index is originated from specially designed } \\
\text { procedure, which is equal to modification of past working } \\
\text { behavior and performance. }\end{array}$ \\
\hline $\mathrm{E}$ & $\begin{array}{l}\text { Merge the financial and non-financial indexes } \\
\text { to represent the attention to short-term benefits } \\
\text { and also the index construction rule of long- } \\
\text { term development. The index focuses on } \\
\text { working result and procedure. }\end{array}$ & $\begin{array}{l}\text { The financial indexes as the main indexes, with non-financial } \\
\text { indexes as the auxiliary indexes, the performance appraisal is } \\
\text { mainly for past working result, and performance improvement for } \\
\text { past performance issue, which is disconnected to strategic } \\
\text { development of enterprise. }\end{array}$ \\
\hline $\mathrm{F}$ & $\begin{array}{l}\text { Set the key performance index to efficiently } \\
\text { merge the individual objective with } \\
\text { organizational object to help individual } \\
\text { objective and enterprise strategic objective to } \\
\text { achieve win-win. }\end{array}$ & $\begin{array}{l}\text { The achievement of performance appraisal index and enterprise } \\
\text { strategic objective is not well connected, but closely related to } \\
\text { level of performance of staff, which is conducive to improvement } \\
\text { of individual performance. }\end{array}$ \\
\hline
\end{tabular}

\subsection{Design method of KPI index system}

In the course of preparing KPI performance index of university teacher, the rule of definition, measurableness, attainableness, relevance and practicality shall be met, which are collectively called SMART rule, as shown in Figure 2.

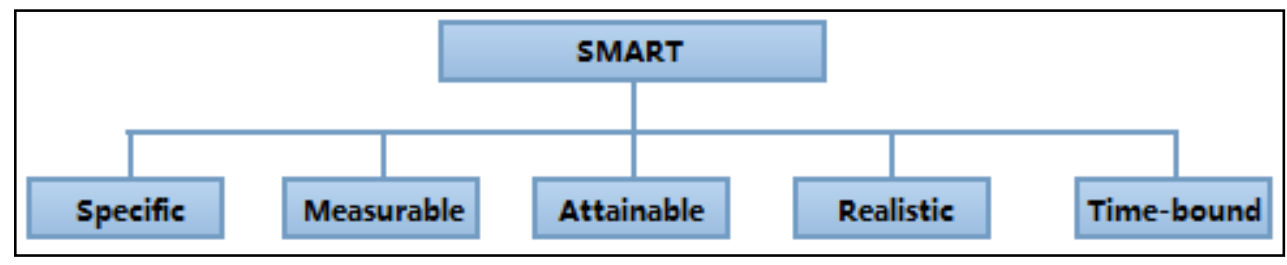

Figure 2. SMART rule.

The design method of KPI performance appraisal system is as shown below:

1) Clarify the development strategy of enterprise, referred to as clarifying the development strategy of university in this article.

2) Propose the key fields that affect the corporation development, referred to as the key fields that refine the university development.

3) Clarify the key performance index in each field, referred to as clarifying the key performance index in the key fields.

4) Determine the appraisal structure and index weight.

5) Apply the performance appraisal system.

6) Manage the appraisal result and focus on feedback and communication.

Use the SWOT analysis method shown in Table 2 for planning of development strategy in university.

Table 2. Analysis method of development and strategic planning in university based on SWOT.

\begin{tabular}{|l|l|}
\hline Superiority S & Weakness W \\
\hline Opportunity O & Threat T \\
\hline
\end{tabular}

\section{Abstraction of key qualities and differ- ential analysis of university teachers}

The quality types of university teachers can be divided into N1 teaching quality, N2 scientific research quality, N3 basic skill quality, N4 scope of knowledge, N5 moral quality, N6 professional quality of teacher, N7 mental quality and N8 social role. The above eight types of qualities for university teachers can be further subdivided into N11 teaching cognition quality, N12 teaching operation quality, N13 teaching monitoring quality, N14 teaching extension quality, N15 teaching design quality, N21 scientific research orientation ability, N22 theoretical thinking ability, N23 practical ability, N24 scientific research creativeness, N25 scientific research organization ability, N26 evaluation and analysis ability, N31 interpersonal relationship coordination ability, N32 analysis ability, N33 innovative ability, N34 study ability, N35 information collection ability, N41 professional scope of knowledge, N42 scope of knowledge in other subjects, N51 political quality, N52 ideological quality, N53 moral quality, N61 expression ability, N62 occupational care degree, N63 occupational sense of responsibility, N64 cultivation ability, N65 rigor of scholarship, N66 occupational sense of value, N71 physical quality, N72 emotion- 
al quality, N73 will, N74 external quality, N81 ability in service and professional field and N82 ability to serve the society, 33 items in total. The first number $\mathrm{i}$ in Nij refers to quality type, $\mathrm{J}$ to the sub-quality under a certain quality type, and Nij to the jth sub-quality under the i type of quality.

The abstracted key qualities of university teachers consist of 33 sub-qualities in the 8 types of quality. The expert interview method shall be used for those 33 subqualities, expecting to screen out the key qualities to lay the foundation for design of key indexes in KPI. Every quality will be graded, and the quality with higher grade will be of higher criticality, and lower grade of lower criticality. The grading standard will be divided into five levels, in which the 5 grade is the highest, 1 is the lowest, and the grades in the middle will be further divided in order and equal distance. The grading result of criticality of sub-quality is obtained by subtracting one highest and lowest grade and calculating the average of the remaining grades, of which the result will be the criticality degree of the sub-quality. Table 3 shows the grading result of criticality degree for each sub-quality.

Table 3. List of grading result of criticality degree for each sub-quality in university teachers.

\begin{tabular}{llllllll}
\hline Sub-quality & Criticality & Sub-quality & Criticality & Sub-quality & Criticality & \multicolumn{2}{l}{ Sub-quality with top 10 grades } \\
\hline N11 & 3.7818 & N31 & 3.8273 & N62 & 4.1273 & Sub-quality & Criticality \\
N12 & 4.2636 & N32 & 4.4545 & N63 & 4.3727 & N66 & 4.5273 \\
N13 & 3.9636 & N33 & 4.3091 & N64 & 4.2455 & N41 & 4.4909 \\
N14 & 4.3545 & N34 & 4.1636 & N65 & 4.2091 & N32 & 4.4545 \\
N15 & 4.3182 & N35 & 4.3636 & N66 & 4.5273 & N63 & 4.3727 \\
N21 & 3.6818 & N41 & 4.4909 & N71 & 3.2727 & N35 & 4.3636 \\
N22 & 3.8818 & N42 & 3.8273 & N72 & 3.2636 & N14 & 4.3545 \\
N23 & 4.0545 & N51 & 3.1455 & N73 & 3.4182 & N15 & 4.3182 \\
N24 & 3.6182 & N52 & 3.7091 & N74 & 3.1545 & N33 & 4.3091 \\
N25 & 4.2636 & N53 & 4.2273 & N81 & 3.8182 & N12 & 4.2636 \\
N26 & 3.4273 & N61 & 3.8636 & N82 & 3.5455 & N25 & 4.2636 \\
\hline
\end{tabular}

Known from Table 3, the main sub-qualities that affect the performance of university teacher are respectively occupational sense of value, professional knowledge, professional knowledge, analysis ability, occupational sense of responsibility, information collection ability, teaching extension quality, teaching design quality, teaching design quality, innovative quality, teaching operation quality and scientific research organization ability.

By using the Formula (3) to conduct the type and degree classification and standardization of criticality of eight types of qualities for university teachers, the gradient levels of each type of criticality will be obtained, as shown in Table 4.

$$
\left\{\begin{array}{l}
\mathrm{Ni}=\frac{1}{\mathrm{ni}} \sum_{\mathrm{j}=1}^{\mathrm{ni}} \mathrm{Nij},(\mathrm{i}=1 \sim 8, \mathrm{j}=1 \sim \mathrm{ni}) \\
\alpha_{i}=\mathrm{Ni} / \sum_{\mathrm{i}=1}^{8} \mathrm{~N}_{\mathrm{i}}
\end{array}\right.
$$

Where ni in Formula (3) represents the number of sub-quality under the ith type of quality.

Table 4. Gradient levels of each type of criticality for university teachers.

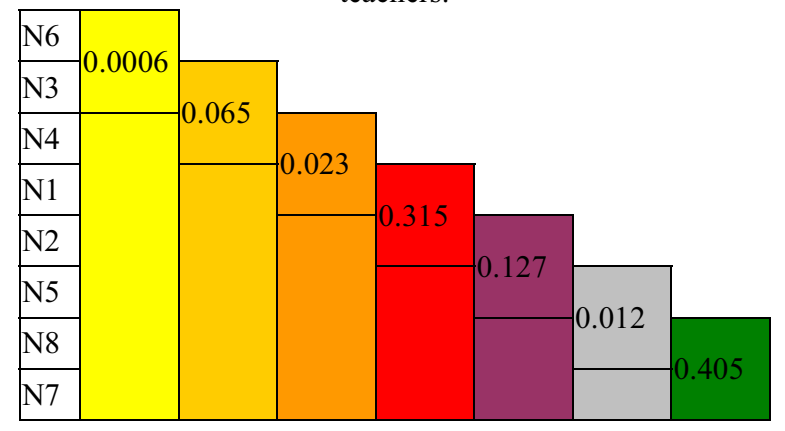

Known from the grading gradient levels in Table 4, the highest difference of N1 teaching quality and N2 scientific quality is 0.315 , and the lowest difference of N6 professional quality of teacher and N3 basic skill quality is 0.006 . According to gradient levels, the eight types of teaching quality can be divided into core level, middle level, external level and boundary level, among which the core level comprises N6, N3, N4 and N1, middle level N2, external level N5 and N8, and boundary level N7. Therefore Figure 3 that shows key quality of university teachers is obtained.

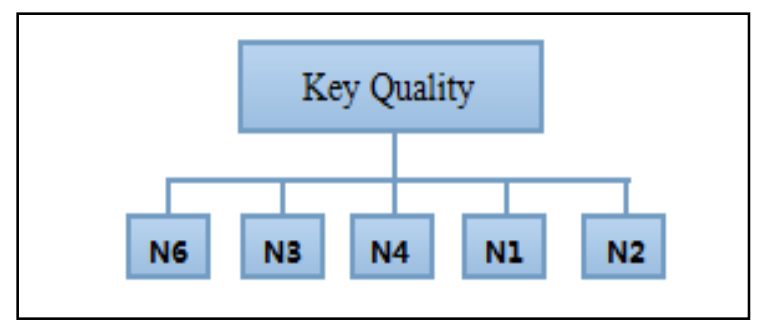

Figure 3. Key quality of university teacher.

\section{Establishment of university teachers' performance assessment index system and assessment method}

To determine the detailed items of key quality of university teacher, the appraisal items can be refined in the subqualities with top 10 grades of five types of N6, N3, N4, $\mathrm{N} 1$ and N2 qualities. The sub-qualities of N6 type quality required for refinement are N66 and N63, and the refined contents of index are respectively M61 language expression, M62 occupational attitude and M63 occupational sense of responsibility; the contents of index refined in sub-qualities N32, N33 and N35 of N3 are M31 interper- 
sonal relationship coordination ability, M32 analysis ability, M33 innovative ability, M34 study ability and M35 information collection ability; the contents of index refined in sub-quality N41 of N4 are M41 professional scope of knowledge and M42 scope of knowledge in other subjects; the contents of index refined in subqualities N12, N14 and N15 of N1 are M11 teaching attitude, M12 teaching content, M13 teaching method, M14 teaching effect and M15 guiding the student thesis and practicality; the contents of index refined in subquality N25 of N2 are M21 number of works, M22 num- ber of thesis publication, M23 result transformation condition, M24 scientific research award, M25 scientific research result and M26 the number of obtained scientific research topics.

The index contents refined above are the ones that can be quantified, behavioral and compliant to the theoretical requirement of KPI performance appraisal index. For operability of performance appraisal, this article provides the weight of performance appraisal index of key quality of university teacher in Table 5 by questionnaire, expert interview and AHP analysis method.

Table 5. List of weight of each index in performance appraisal system of key quality.

\begin{tabular}{|c|c|c|c|c|c|c|c|c|c|c|}
\hline \multicolumn{2}{|c|}{ Index symbol } & \multirow{3}{*}{$\begin{array}{l}\text { Weight } \\
0.20 \\
0.15\end{array}$} & \multicolumn{2}{|c|}{ Index symbol } & \multirow{2}{*}{$\begin{array}{l}\text { Weight } \\
0.020 \\
\end{array}$} & \multicolumn{2}{|c|}{ Index symbol } & Weight & Index symbol & Weight \\
\hline \multirow{5}{*}{$\begin{array}{l}\text { First class } \\
\text { index }\end{array}$} & N1 & & \multirow{7}{*}{$\begin{array}{l}\text { Second } \\
\text { class } \\
\text { index }\end{array}$} & M13 & & \multirow{7}{*}{$\begin{array}{l}\text { Second } \\
\text { class } \\
\text { index }\end{array}$} & M25 & 0.060 & \multirow{2}{*}{\multicolumn{2}{|c|}{ Second class index }} \\
\hline & $\mathrm{N} 2$ & & & M14 & 0.060 & & M26 & 0.040 & & \\
\hline & N3 & 0.25 & & M15 & 0.070 & & M31 & 0.020 & M41 & 0.150 \\
\hline & N4 & 0.20 & & M21 & 0.008 & & M32 & 0.090 & M42 & 0.050 \\
\hline & N6 & 0.20 & & M22 & 0.030 & & M33 & 0.050 & M61 & 0.050 \\
\hline \multirow{2}{*}{$\begin{array}{l}\text { Second } \\
\text { class index }\end{array}$} & M11 & 0.02 & & M23 & 0.007 & & M34 & 0.030 & M62 & 0.070 \\
\hline & M12 & 0.03 & & M24 & 0.005 & & M35 & 0.060 & M63 & 0.080 \\
\hline
\end{tabular}

Different levels of teacher's quality can be obtained according to the list of weight and quantified quality grade of teacher, by which it can go through the course of performance appraisal.

\section{Conclusions}

This article describes the importance of performance appraisal in human resources of university teachers and, based on factors related to performance and KPI theory, discusses the establishment method of performance appraisal index system of university teacher based on KPI, as well as establishes quality evaluation system of university teacher consisting of five key qualities and conducts an empirical analysis on weight determination of each index.

It is concluded as below:

1) The quantity of index in performance appraisal index system of university teacher can be quantified and behavioral, compliant to the rule of KPI theory.

2) The key qualities reflecting the university teachers are N6 professional quality of teacher, N3 basic skill quality, N4 scope of knowledge, N2 scientific research quality and N1 teaching quality.

3) The key qualities reflecting the university teachers are N66 occupational sense of value, N41 professional knowledge, N32 analysis ability, N63 occupational sense of responsibility, N35 information collection ability, N14 teaching extension quality, N15 teaching design quality, N33 innovative ability, N12 teaching operation quality and N25 scientific research organization ability.

4)The index content of definition refined by 10 key sub-qualities consists of 21 qualities, respectively including language expression, occupational attitude, occupational sense of responsibility, interpersonal relationship coordination ability, analysis ability, innovative ability, study ability, information collection ability, professional scope of knowledge, scope of knowledge in other subjects, teaching attitude, teaching content, teaching method, teaching effect, guiding student thesis and practicality, number of works, number of thesis publication, result transformation condition, scientific research award, scientific research result and number of obtained scientific research topics.

\section{References}

1. Lidong Lu. Performance Management System of Zhejiang Construction Group Construction Enterprise [D]. Hangzhou: Zhejiang University, 2008.

2. Qian Lu. Analysis of the performance management system of KPI For Small And Medium Enterprises based on KPI [J]. China Trade. 2011, (2):54-55.

3. Jingang Shao. The Design of Performance Appraisal System for J Company Based on KPI [D]. Kaifeng: Henan University, 2013.

4. Chaonan Liu. 360 Degree Performance Appraisal Research on Personnel in High-tech Enterprises Based on KPI [D]. Harbin: Harbin University of Science and Technology, 2012.

5. Yu Shi Dong. An empirical study of enterprise performance evaluation system based on KPI [J]. Commercial Era. 2009(11):30-32.

6. Wei Liu. Application Research on KPI in Performance Evaluation Of University Teachers [D]. Chongqing: Chongqing University, 2007.

7. Shusong Zhao . An empirical research on impact of the relation performance appraisal on knowledge sharing behavior for personnel [J]. Journal of Management, 2013, 10 (9):1323-1330.

8. Shuying Sun. An empirical study of the con-struction of evaluation index system for enterprise marketing performance in China [J]. China Soft Science, 2006, (1): 137-137. 